\title{
KESIAPAN MASYARAKAT DALAM PEMENUHAN KEBUTUHAN KEPARIWISATAAN SEBAGAI DAYA TARIK WISATA DI KAMPUNG JAWI, KECAMATAN GUNUNGPATI, KOTA SEMARANG
}

\author{
HENDRIANTO SUNDARO ${ }^{a}$, EVA YULIANI ${ }^{\mathrm{b}}$ \\ aUniversitas Semarang; Jl. Soekarno Hatta, RT.7/RW.7, Tlogosari Kulon, Kec. Pedurungan, Kota Semarang ; \\ evayuliani346@gmail.com \\ bUniversitas Semarang; JI. Soekarno Hatta, RT.7/RW.7, Tlogosari Kulon, Kec. Pedurungan, Kota Semarangi; \\ Hendri01190@gmail.com
}

Info Artikel:

- Artikel Masuk: 22/10/21

- Artikel diterima: $31 / 10 / 21$

- Tersedia Online: 31/12/21

\begin{abstract}
ABSTRAK
Dengan luas wilayah 24 Ha, Kampung Jawi yang berada di Kelurahan Sukorejo, Kecamatan Gunungpati, Kota Semarang menyimpan banyak potensi daya tarik wisata dengan mengupayakan pemenuhan kebutuhan kepariwisataan. Namun demikian, upaya tersebut harus diimbangi dengan kesiapan masyarakat dalam pemenuhan kebutuhan kepariwisataan sehingga pariwisata dapat berkelanjutan. Penelitian ini mengkaji bagaimana kesiapan masyarakat Kampung Jawi, Kecamatan Gunungpati, Kota Semarang dalam melakukan pemenuhan kebutuhan kepariwisataan. Tujuan dari penelitian ini adalah untuk mengidentifikasi kesiapan masyarakat yang meliputi pengetahuan, sikap dan respon dalam pemenuhan kebutuhan kepariwisataan yaitu atraksi, akomodasi, aksesbilitas, fasilitas wisata dan layanan masyarakat. Pendekatan yang digunakan dalam penelitian ini adalah pendekatan Kuantitatif. Data diperoleh melalui kuesioner. Analisis data dilakukan dengan menggunakan teknik analisis community readiness model dan Analysis Hierarki Poses (AHP). Dari hasil perhitungan analisis community readines model diperoleh informasi tingkat kesiapan masyarakat dari segi pengetahuan yakni komponen atraksi mendapat nilai terbesar untuk dikembangkan yaitu 30,7\%. Untuk segi sikap, komponen atraksi juga mendapat nilai prioritas utama untuk dikembangkan yaitu $27 \%$ dan dari segi respon, komponen aksesbilitas memiliki nilai tertinggi untuk dikembangkan yaitu sebesar $26,6 \%$. Hasil tersebut menunjukkan bahwa masyarakat kampung jawi menganggap komponen atraksi memiliki peranan penting untuk dijadikan sebagai daya tarik wisata selain itu komponen aksesbilitas juga dianggap penting untuk menambah daya tarik wisata.
\end{abstract}

Kata Kunci: Kesiapan Masyarakat, Kebutuhan Kepariwisataan, Daya tarik wisata, Kampung Jawi

\begin{abstract}
With an area of 24 hectares, Kampung Jawi which is located in Sukorejo Village, Gunungpati District, Semarang City has a lot of potential for tourist attractions by seeking to fulfill tourism needs. However, these efforts must be balanced with the readiness of the community in meeting tourism needs so that tourism can be sustainable. This study examines how the readiness of the people of Kampung Jawi, Gunungpati District, Semarang City in fulfilling tourism needs. The purpose of this study is to identify community readiness which includes knowledge, attitudes and responses in meeting tourism needs, namely attractions, accommodation, accessibility, tourist facilities and community services. The approach used in this study is a quantitative approach. Data obtained through questionnaires. Data analysis was carried out using community readiness model analysis techniques and Analysis Hierarchy Poses (AHP). From the calculation results of the analysis of the community readings model, information on the level of community readiness in terms of knowledge is obtained, namely the attraction component gets the largest value to be developed, which is $30.7 \%$. In terms of attitude, the attraction component also gets a top priority value to be developed, which is $27 \%$ and in terms of response, the accessibility component has the highest value to be developed, which is $26.6 \%$. These results indicate that the people of Kampung Jawi consider the attraction component to have an important role to serve as a tourist attraction. In addition, the accessibility component is also considered important to increase tourist attraction.
\end{abstract}

Keywords: Community Readiness, Tourism Needs, Tourist Attraction, Kampung Jawi 


\section{PENDAHULUAN}

Desa Wisata merupakan bentuk kepariwisataan dengan memanfaatkan potensipotensi yang dimiliki oleh suatu desa. Pada satu sisi Desa Wisata memberikan peluang besar bagi kesejahteraan masyarakat dalam kegitan wisata tersebut namun disisi lain memiliki tantangan bagi masyarakat dalam mengelola kegiatan agar pariwisata tersebut dapat berkembang. Dalam pengembangan Desa Wisata perlu adanya penawaran wisata yang bisa dijadikan sebagai daya Tarik terhadap wisatawan. Faktor-faktor daya Tarik wisata salah satunya adalah terpenuhinya kebutuhan kepariwisataan, menurut teori Tourism Western Australia pemenuhan kebutuhan kepariwisataan diantaranya adalah attraction, accessbility, accommodation, amenities dan awareness atau dikenal dengan 5 A's Tourism. Dalam upaya terpenuhinya kebutuhan kepariwisataan tentunya melibatkan masyarakat lokal. Hal ini tentunya berpengaruh terhadap kesiapan masyarakat lokal dalam memenuhi kebutuhan kepariwisataan. Menurut Rapopor 1997 (dalam Fahmi Lazuardi Ramadhan, 2015) prinsip kesiapan masyarakat meliputi pengetahuan, sikap, dan respon. Kalialang Lama (bagian RW 1) Kampung Jawi Kelurahan Sukorejo, Kecamatan Gunungpati merupakan Desa Wisata yang ada di Kota Semarang yang diresmikan pada tahun 2018 dengan mengangkat potensi berupa kebudayaan jawa yang bertujuan untuk menjaga nilai-nilai masyarakat dan pelestarian kebudayaan jawa. Luas wilayahnya sebesar $24 \mathrm{Ha}$. Kampung Jawi merupakan Program pengembangan Desa Wisata yang dipelopori oleh ketua RW Kampung Kalialang lama yang kemudian diresmikan oleh pemerintah Semarang. Pada awal mula terbentuknya Desa Wisata Kampung Jawi, masyarakat belum mengetahui terkait apa saja kebutuhan kepariwisataan yang dijadikan sebagai daya tarik wisata dan bagaimana agar menjadi pariwisata yang berkelanjutan. Masyarakat berjalan dengan keinginannya masing-masing dan tidak mau diajak bekerja sama untuk mencapai kepentingan pariwisata yang berkelanjutan, hal ini menjadi masalah pada kesiapan baik secara teknis perencanaan wisata maupaun dalam proses pengembangannya. Untuk membuat perencanaan pengembangan kedepannya maka perlu diketahui posisi kesiapan masyarakat dalam program desa wisata dimana menurut Edwards, R.W et. Al, (2000) menyatakan ada 9 tahap posisi kesiapan masyarakat terhadap suatu program yaitu: no awareness, denial, vague awareness, preparation, preplanning, initation, stabilization, confirmation dan professionalization

Penelitian ini bertujuan untuk mengkaji mengenai kesiapan masyarakat Kampung Jawi dalam melakukan pemenuhan kebutuhan kepariwisataan sebagai upaya penawaran dan daya Tarik wisata yang berkelanjutan. adapun output/hasil penelitian ini diharapkan dapat bermanfaat dalam menambah keilmuan mengenai faktor daya tarik wisata budaya yang berbasis kesiapan masyarakat. Keilmuan ini dapat memperkaya penelitian dalam bidang Perencanaan Wilayah dan Kota dalam pengembangan wilayah khususnya di bidang pariwisata. Selain itu, hasil dari penelitian ini juga dapat bermanfaat bagi masyarakat sekitar khususnya masyarakat Kampung Jawi untuk eveluasi mengenai hal-hal yang perlu dikembangkan untuk kedepannya.

\section{DATA DAN METODE}

Metode penelitian yang digunakan yaitu metode kuantitatif dengan menggunakan data angka/numerik, untuk menguji teori dan mengungkap fakta dengan cara deduktif. Metode pengumpulan data bersumber dari data primer dan sekunder. Data primer berupa data observasi lapangan dan data kuesioner, data sekunder berupa kajian dokumen.

Penentuan sampling dilakukan dengan 2 cara. Pertama, untuk menentukan tingkatan dan posisi kesiapan masyarakat digunakan perhitungan slovin (Ariola, 2006). Dari hasil perhitungan diperoleh jumlah sample sebanyak 35 orang. Kedua, menentukan jumlah sampling untuk penentuan prioritas pengembangan pemenuhan kebutuhan kepariwisataan oleh masyarakat dengan menggunakan quota sampling sebanyak 10 responden.

Data yang telah dipeoleh kemudian diolah dengan menggunakan teknik analisis community readiness model dan teknik analisis hierarki proses. Analisis community readines model digunakan untuk mengidentifikasi kesiapan masyarakat berdasarkan indikator pengetahuan, sikap dan respon sedangkan 
analisis hierarki proses (AHP) digunakan untuk menentukan prioritas pengembangan kesiapan masyarakat dalam pemenuhan kebutuhan wisata.

\section{HASIL DAN PEMBAHASAN}

\section{Analisis Tingkat Kesiapan Masyarakat}

Pada analisis tingkat kesiapan dilakukan dengan mempresentasikan masing - masing hasil dari nilai kesiapan masyarakat dari segi pengetahuan, sikap dan respon terkait pemenuhan kebutuhan kepariwisataan. Adapun tujuannya adalah untuk mengetahui variabel mana yang memiliki nilai terendah dan nilai tertinggi sehingga dapat dijadikan evaluasi untuk rencana kedepannya

Tabel 1. Hasil Kuesioner Tingkat dan Posisi Kesiapan Masyarakat

\begin{tabular}{|l|l|l|c|}
\hline No & Sub Variabel & \multicolumn{1}{|c|}{ kriteria } & Nilai \\
\hline 1 & Pengetahuan & Atraksi & 368 \\
\hline & & Aksesbilitas & 345 \\
\hline & & Akomodasi & 376 \\
\hline & & Amenities & 371 \\
\hline 2 & sikap & Awarness & 418 \\
\hline & & Atraksi & 430 \\
\hline & & Aksesbilitas & 402 \\
\hline & & Akomodasi & 398 \\
\hline & & Amenities & 450 \\
\hline 3 & Respon & Awarness & 426 \\
\hline & & Atraksi & 362 \\
\hline & & Aksesbilitas & 375 \\
\hline & & Akomodasi & 322 \\
\hline & & Awenities & 375 \\
\hline
\end{tabular}

Sumber: Hasil analisis, 2021

Adapun hasil analisis terhadap tingkat kesiapan masyarakat adalah sebagai berikut:

\section{Variabel Pengetahuan}

Variabel pengetahuan dimaksudkan untuk mengidentifikasi pengetahuan masyarakat di Kampung jawi terhadap kebutuhan kepariwisataan. Informasi ini dimaksudkan agar posisi pengetahuan masyarakat Kampung Jawi dapat diketahui sehingga dapat dijadikan dasar intervensi untuk pengembangan Kampung Jawi.

Berdasarkan data kuesioner diketahui bahwa pengetahuan masyarakat Kampung Jawi dalam memenuhi kebutuhan wisata yaitu sebagai berikut:

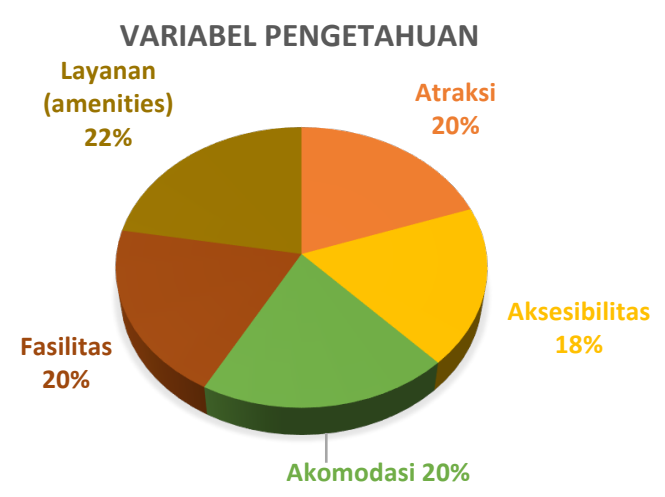

Sumber: Hasil analisis. 2021

Gambar 1. Presentase tingkat kesiapan masyarakat dari segi pengetahuan dalam pemenuhan kebutuhan kepariwisataan

Pada Gambar 1 diketahui bahwa tingkat pengetahuan terhadap pemenuhan kebutuhan wisata dari segi layanan masyarakat (awarness) menjadi nilai kesiapan tertinggi yakni $22 \%$. Artinya, masyarakat Kampung Jawi sudah banyak yang mengetahui bagaimana cara memberikan pelayanan yang baik kepada wisatawan, yaitu dengan memberikan pelayanan jasa yang dapat dinikmati oleh wisatawan serta bersikap ramah dalam berinteraksi dengan wisatawan. Sedangkan dari segi aksesbilitas mendapat nilai kesiapan terendah yakni sebesar 18\%. Artinya masyarakat belum mengetahui bagaimana upaya menciptakan kemudahan akses baik akses transportasi maupun akses media informasi. Mesakipun masyarakat Kampung Jawi sudah memiliki wadah media informasi namun belum optimal karena masih kurang ideide kreatif dalam membuat konten yang dapat menarik wisatawan untuk berkunjung.

\section{Variabel Sikap}

Variabel sikap dimaksudkan untuk mengidentifikasi derajat sikap positifr masyakat dalam pemenuhan kebutuhan kepariwisataan. Semakin tinggi derajat penerimaannya maka semakin tinggi pula kesiapan masyarakat dari variabel sikap di dalam pemenuhan kebutuhan kepariwisataan.

Berdasarkan data kuesioner diketahui bahwa variabel sikap masyarakat Kampung 
Jawi dalam memenuhi kebutuhan wisata adalah sebagai berikut:

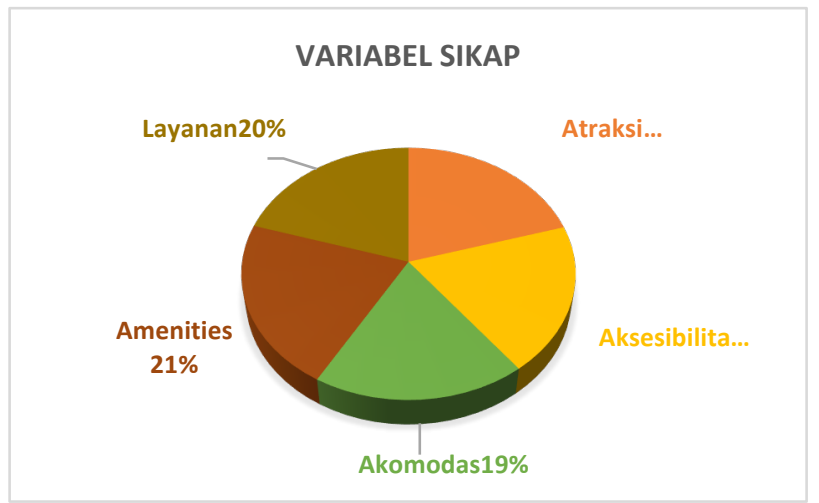

Sumber: Hasil analisis. 2021

Gambar 2. Presentase tingkat kesiapan masyarakat dari segi sikap dalam pemenuhan kebutuhan kepariwisataan

Pada Gambar 2 diketahui bahwa sikap masyarakat terhadap pemenuhan kebutuhan wisata dari segi atraksi dan amenities (fasilitas wisata) menjadi nilai kesiapan tertinggi yakni masing-masing sebesar $21 \%$. Sedangkan dari segi aksesbilitas dan akomodasi mendapat nilai kesiapan terendah yakni masing-masing sebesar $19 \%$.

Dalam pemenuhan kebutuhan wisata di Kampung Jawi masyarakat rata-rata sudah memberikan sikap yang positif. Berdasarkan data kuesioner yang dilakukan rata-rata masyarakat menjawab bahwa masyarakat membutuhkan motivasi dalam upaya pengembangannya adapun yang menjadi motivasi masyarakat adalah peningkatan kesejahteraan. Sikap positif masyarakat terhadap adanya desa wisata Kampung Jawi dapat dilihat dari adanya keikutsertaan masyarakat dalam proses pengembangannya dengan mulai membuat ide-ide kreatif serta inovatif, masyarakat juga menjadi termotivasi untuk terus mengembangkan Kampung Jawi.

\section{Variabel Respon}

Variabel respon dimaksudkan untuk
mengukur tanggapan dalam bentuk
tindakan/dukungan yang dilakukan oleh
masyarakat sebagai implementasi faktor
pengetahuan dan sikap. Berdasarkan data
kuesioner diketahui bahwa variabel respon
masyarakat Kampung Jawi dalam memenuhi
kebutuhan wisata yaitu sebagai berikut:

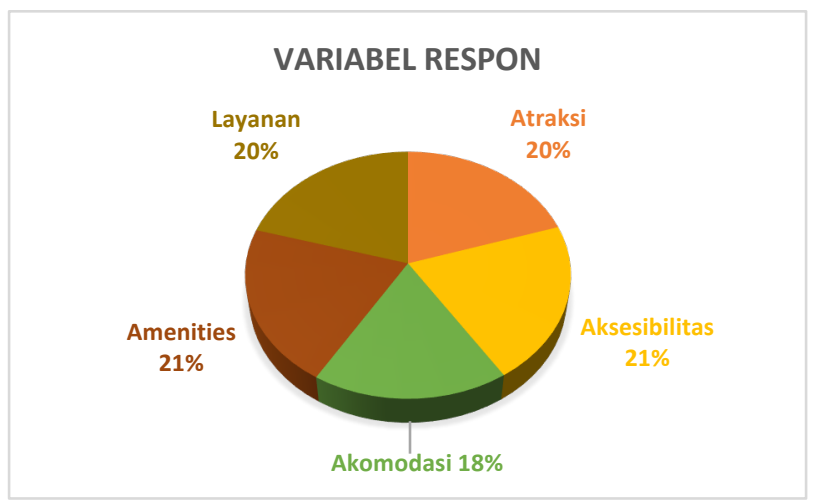

Sumber: Hasil analisis. 2021

Gambar 3. Presentase tingkat kesiapan masyarakat dari segi respon dalam pemenuhan kebutuhan kepariwisataan

Pada Gambar 3 diketahui bahwa tingkat respon terhadap pemenuhan kebutuhan wisata dari segi amenities dan aksesbilitas menjadi nilai kesiapan tertinggi yakni sebesar $21 \%$. Sedangkan dari segi akomodasi mendapat nilai kesiapan terendah yakni $18 \%$.

Dalam pemenuhan kebutuhan wisata di Kampung Jawi masyarakat rata-rata sudah memberikan respon yang cukup baik karena sudah ada implementasi wujud dukungan dari sikap yang diberikan baik dari segi atraksi, aksesbilitas, akomodasi, fasilitas wisata maupun layanan masyarakat.

Implementasi dukungan yang ada di Kampung Jawi dalam pemenuhan kebutuhan wisata diantaranya adalah adanya pelatihan dan sosialisasi untuk pengadaan kesenian atraksi wisata, adanya lembaga pengelelolaan Kampung Jawi untuk upaya pengembangan dan strategi, adanya dukungan dari masyarakat dalam pengadaan kebutuhan kepariwisataan.

\section{Analisis Posisi Kesiapan Masyarakat}

Analisis ini dilakukan untuk mengidentifikasi posisi kesiapan masyarakat Kampung Jawi dimana menurut Edwards, R.W et. Al, (2000) menyatakan jika ada 9 tahap posisi kesiapan masyarakat terhadap suatu program yaitu : no awareness, denial, vague awareness, preparation, preplanning, initation, stabilization, confirmation dan professionalization.

Untuk mengetahui posisi kesiapan masyarakat di Kampung Jawi langkah pertama yang dilakukan adalah dengan mencari nilai kesiapan masyarakat setiap variabel yang diolah dari data kuesioner sebelumnya. Adapun 
hasil analisis posisi kesiapan masyarakat di Kampung Jawi adalah sebagai berikut.

Tabel 2. Nilai Kesiapan Masyarakat

\begin{tabular}{|l|l|c|c|}
\hline No & Sub Variabel & $\begin{array}{c}\text { Jumlah Nilai } \\
\text { per } \\
\text { Variabel/3 } \\
\text { (Pertanyaan } \\
\text { Kuesioner) }\end{array}$ & $\begin{array}{c}\text { Nilai }(\boldsymbol{\Sigma} \mathbf{X} \\
\text { IJumlah } \\
\text { responden) }\end{array}$ \\
\hline 1 & Pengetahuan & 626 & 17,9 \\
\hline 2 & Sikap & 702 & 20,1 \\
\hline 3 & Respon & 601 & 17,1 \\
\hline
\end{tabular}

Sumber: Hasil analisis. 2021

Berdasarkan tabel diatas dapat diketahui dimana nilai untuk variabel pengetahuan adalah 17,9 variabel sikap 20,1 dan Variabel respon adalah 17,1 . Untuk langkah berikutnya adalah menghitung Nilai kesiapan masyarakat dikampung Jawi dengan rumus berikut :

$\mathrm{NKM}: \underline{\Sigma X 1}+\Sigma \mathrm{X} 2+\Sigma \mathrm{X} 3$ Jumlah Responden

Dimana:

$\Sigma X 1$ : jumlah nilai variabel pengetahuan/ 3 (Pertanyaan di tiap sub variabel)

$\Sigma X 2$ : jumlah nilai variabel Sikap /3 (Pertanyaan di tiap sub variabel)

$\Sigma X 3$ : jumlah nilai variabel Respon / 3 (Pertanyaan di tiap sub variabel)

Adapun perhitungannya adalah sebagai berikut:

$$
\begin{aligned}
\text { NKM } & : \frac{\Sigma X 1+\Sigma X 2+\Sigma X 3}{\text { Jumlah Responden }} \\
& : \frac{626+702+601}{35} \\
& : \frac{1.929}{35} \\
& : 55
\end{aligned}
$$

Untuk langkah selanjutnya yaitu menghitung point kesiapan masyarakat dengan rumus sebagai berikut:

PKM : NKM

Jumlah variabel

$$
\begin{aligned}
& : \frac{55}{3} \\
& : 18,3
\end{aligned}
$$

Setelah diketahui point kesiapan Masyarakat untuk mengetahui posisi kesiapan masyarakat di Kampung Jawi maka dicari interval selisih untuk nilai di setiap posisi kesiapan. Untuk menghitung nialai interval yaitu dengan rumus berikut:

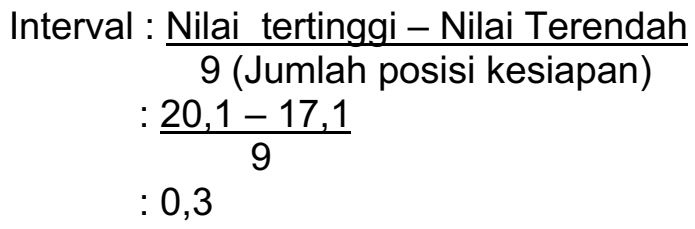

\begin{tabular}{|c|c|c|}
\hline No & Tahap & Nilai skor \\
\hline 1 & $\begin{array}{l}\text { No Awareness (tidak ada } \\
\text { kesadaran) }\end{array}$ & $17,1-17,4$ \\
\hline 2 & Denial (Penyangkalan) & $17,5-17,8$ \\
\hline 3 & $\begin{array}{l}\text { Vague Awarennes (kesadaran } \\
\text { samar) }\end{array}$ & $17.9-18,2$ \\
\hline 4 & Prepration (pra perencanaan) & $18,3-18,6$ \\
\hline 5 & Preplanning (persiapan) & $18,7-19$ \\
\hline 6 & Initiation (inisiasi) & $20-20,3$ \\
\hline 7 & Stabilization (stabilisasi) & $20,4-20,7$ \\
\hline 8 & Confirmation/ Expansio & $20,8-21,1$ \\
\hline 9 & $\begin{array}{l}\text { Professionalization (level } \\
\text { kepemilikan masyarakat }\end{array}$ & $21,2-21,5$ \\
\hline
\end{tabular}

Setelah diketahui interval selisih maka dapat diketahui point pada setiap tahapan yaitu dimulai dari nilai variabel terendah yaitu 17,1 kemudian ditambahkan dengan nilai interval yang sudah dihitung yaitu 0,3 pada setiap tahapan. Berikut ini tabel hasil nilai tahapan posisi kesiapan masyarakat di kampung Jawi

Tabel 3. Posisi Kesiapan Masyarakat

Berdasarkan perhitungan sebelumnya point kesiapan Masyarakat Kampung jawi yaitu sebesar 18,3 dimana menurut tabel posisi kesiapan masyarakat berada pada posisi prepration yaitu posisi dimana masyarakat sudah mulai mengorganisir diri. adapun bentuk organisir diri di Kampung Jawi meliputi adanya keterlibatan masyarakat dalam pengembangan dan pembangunan fasilitas-fasilitas yang ada di Kampung Jawi

Analisis Prioritas Pengembangan Kesiapan Masyarakat dalam Pemenuhan Kebutuhan Kepariwisataan 
Analisis ini dilakukan untuk mengetahui prioritas kesiapan masyarakat yang perlu dikembangkan dalam kebutuhan wisata di Kampung Jawi. Adapun langkah awal yang dilakukan yaitu menyusun struktur hirarki, menghitung pairwise comparison, membuat matriks perbandingan, menentukan prioritas dan melakukan uji konsistensi.

\section{1) Struktur Hirarki}

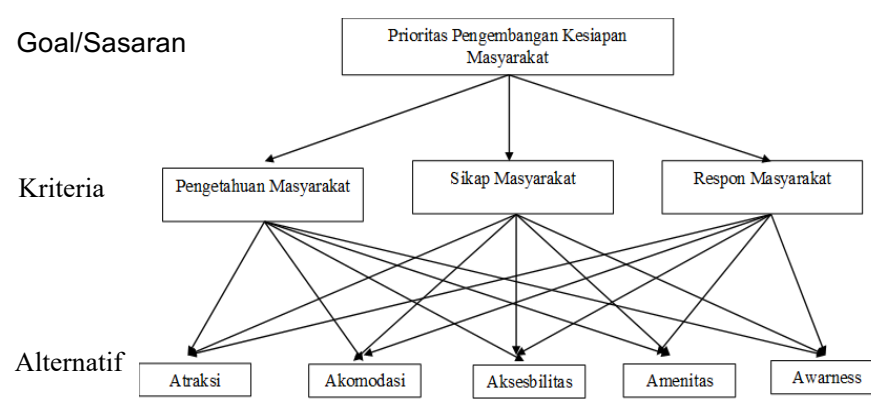

Sumber: Hasil analisis. 2021

Gambar 4. Struktur Hirarki

\section{2) Perhitungan Pairwise Comparison Antar Kriteria (Combined)}

Pada tahap ini dilakukan perhitungan pairwise comparison pada perbandingan berpasangan antar kritria. Adapun langkah yang dilakukan adalah dengan memasukan hasil kuesioner setiap responden ke dalam expert choice kemudian dicari rata-rata geometrik dengan rumus:

$$
10 \sqrt{ } \mathrm{x} 1 . \times 2 \ldots \ldots \ldots \mathrm{xn}
$$

keterangan:

$X$ : hasil pairwise comparison antar kriteria

$\mathrm{N}$ : jumlah total responden

Adapun hasil perhitungan adalah sebgai berikut:

\section{a. Variabel Pengetahuan}

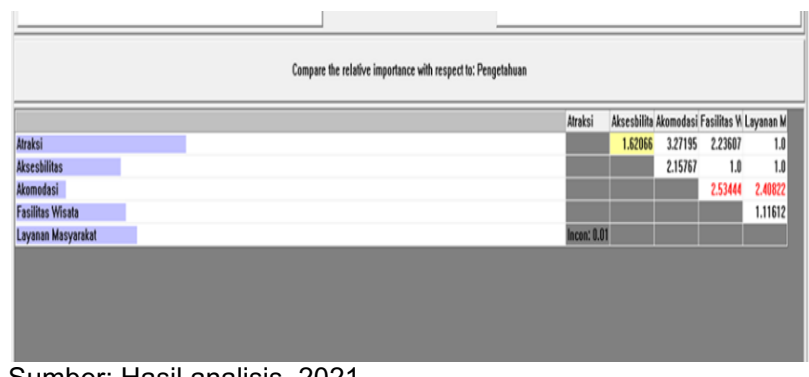

Sumber: Hasil analisis. 2021
Gambar 5. Pairwise Comparison Antar Kriteria Pengetahuan (Combined)

Dari gambar diatas dapat dilihat bahwa hasil perhitungan prioritas pengembangan pengetahuan antar kriteria kebutuhan kepariwisataan adalah sebagai berikut:

a) Atraksi dengan aksesbilitas : 1,62066

b) Atraksi dengan akomodsi : 3,27195

c) Atraksi dengan fasilitas wisata : 2,23607

d) Atraksi dengan layanan masyarakat : 1,0

e) Aksesbilitas dengan akomodasi : 2,15767

f) Aksesbilitas dengan fasilitas wisata : 1,0

g) Aksesbilitas dengan layanan masyarakat $: 1,0$

h) Akomodasi dengan fasilitas wisata : 2,53444

i) Akomodasi dengan layanan masyarakat: 2,40822

j) Fasilitas wisata dengan layana masyarakat : ,11612

Perbandingan berpasangan yang diberikan responden memliki nilai inconsistensy ratio yang lebih kecil dari 0,1 sebagai batas maksimal nilai inconsistensy ratio. Dimana pada gambar hasil perhitungan pada aplikasi expert choiche nilai consistensy ratio sebesar 0,01 dengan begitu hasil perhitungan cukup konsisten.

\section{b. Variabel Sikap}

Dari gambar 6 di awah ini dapat dilihat bahwa hasil perhitungan prioritas pengembangan sikap antar kriteria kebutuhan kepariwisataan adalah sebagai berikut:

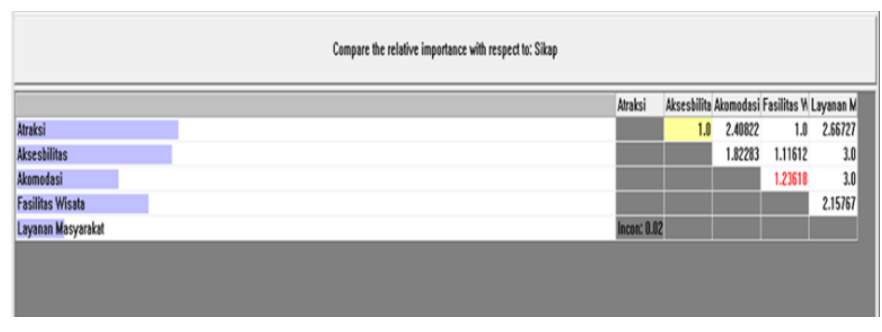

Sumber: Hasil analisis. 2021

Gambar 6. Pairwise Comparison Antar Kriteria Sikap (Combined)

a) Atraksi dengan aksesbilitas : 1,0

b) Atraksi dengan akomodsi : 2,4082 
c) Atraksi dengan fasilitas wisata : 1,0

d) Atraksi dengan layanan masyarakat : 2,66727

e) Aksesbilitas dengan akomodasi : 1,82283

f) Aksesbilitas dengan fasilitas wisata : 1,11612

g) Aksesbilitas dengan layanan masyarakat : 3,0

h) Akomodasi dengan fasilitas wisata : 1,23618

i) Akomodasi dengan layanan masyarakat: 3,0

j) Fasilitas wisata dengan layana masyarakat : 2,15767

Perbandingan berpasangan yang diberikan responden memliki nilai inconsistensy ratio yang lebih kecil dari 0,1 sebagai batas maksimal nilai inconsistensy ratio. Dimana pada gambar hasil perhitungan pada aplikasi expert choiche nilai consistensy ratio sebesar 0,02 dengan begitu hasil perhitungan cukup konsisten.

\section{c. Variabel Respon}

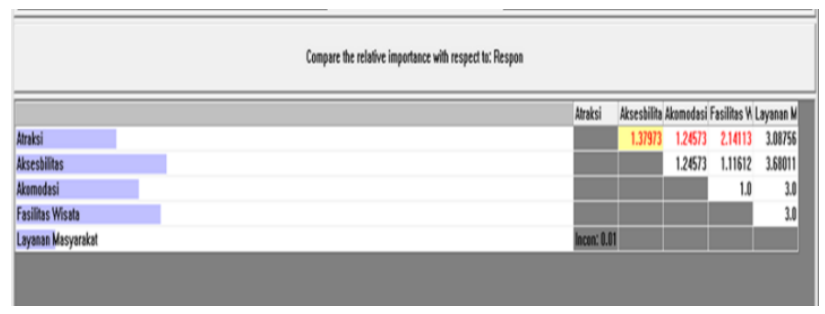

Sumber: Hasil analisis. 2021

Gambar 7. Pairwise Comparison Antar Kriteria Respon (Combined)

Dari gamba 7 diatas dapat dilihat bahwa hasil perhitungan prioritas pengembangan respon antar kriteria kebutuhan kepariwisataan adalah sebagai berikut:

a) Atraksi dengan aksesbilitas : 1,37973

b) Atraksi dengan akomodsi : 1,24573

c) Atraksi dengan fasilitas wisata : 2,14113

d) Atraksi dengan layanan masyarakat : 3,08756

e) Aksesbilitas dengan akomodasi : 1, 24573

f) Aksesbilitas dengan fasilitas wisata : 1,11612

g) Aksesbilitas dengan layanan masyarakat : 3,68011 h) Akomodasi dengan fasilitas wisata : 1,0

i) Akomodasi dengan layanan masyarakat: 3.0

j) Fasilitas wisata dengan layana masyarakat : 3,0

Perbandingan berpasangan yang diberikan responden memliki nilai inconsistensy ratio yang lebih kecil dari 0,1 sebagai batas maksimal nilai inconsistensy ratio. Dimana pada gambar hasil perhitungan pada aplikasi expert choiche nilai consistensy ratio sebesar 0,01 dengan begitu hasil perhitungan cukup konsisten.

\section{3) Matriks Perbandingan Berpasangan}

Setelah diketahui nilai bobot dari masingmasing pilihan antar kriteria maka untuk mengetahui nilai dari masing-masing kriteria dihitung melalui matrikas perbandingan. Adapun hasil dari perhitungan matriks disajikan sebagai berikut:

\section{a. Variabel Pengetahuan}

Untuk menghitung matriks perbandingan yaitu menggunakan bobot nilai yang sudah dihitung pada tabel 4 dimana nilai diletakan pada kolom 1 dan baris 1 untuk perhitungan selanjutnya angka 0,617 pada baris 1 dan kolom 2 merupakan hasil perhitungan dari 1/nilai pada kolom 1 baris 2, dan seterusnya.

\section{b. Variabel Sikap}

Untuk menghitung matriks perbandingan yaitu menggunakan bobot nilai yang sudah dihitung pada tabel 5 dimana nilai diletakan pada kolom 1 dan baris 1 untuk perhitungan selanjutnya angka 1 pada baris 1 dan kolom 2 merupakan hasil perhitungan dari $1 /$ nilai pada kolom 1 baris 2, dan seterusnya.

\section{c. Variabel Respon}

Untuk menghitung matriks perbandingan yaitu menggunakan bobot nilai yang sudah dihitung pada tabel 6 dimana nilai diletakan pada kolom 1 dan baris 1 untuk perhitungan selanjutnya angka 0,725 pada baris 1 dan kolom 2 merupakan hasil perhitungan dari $1 /$ nilai pada kolom 1 baris 2 , dan seterusnya. 
4) Prioritas Pengembangan Kampung Jawi

Untuk langkah selanjutnya adalah perhitungan bobot prioritas dari masing-masing kriteria pada setiap variabel. Adapun tujuannya adalah untuk mengetahui kriteria mana yang memiliki bobot tertinggi sampai dengan terendah. Untuk bobot tertinggi akan menjadi prioritas utama. Adapun hasil perhitungan menggunakan expert choiche adalah sebagai berikut

\section{a. Variabel Pengetahuan}

Berdasarkan Gambar 8 hasil analisis AHP pada kritera pengetahuan atraksi mendapat prioritas utama untuk dikembagkan dengan nilai bobot 0,307 atau $30,7 \%$, kemudian prioritas kedua layanan masyarakat dengan bobot 0,217 atau $21,7 \%$, kemudian fasilitas wisata dengan bobot 0,195 atau $19,5 \%$ aksesbilitas dengan bobot 0,194 atau $19,4 \%$ dan akomodasi dengan bobot 0,086 atau $8,6 \%$.

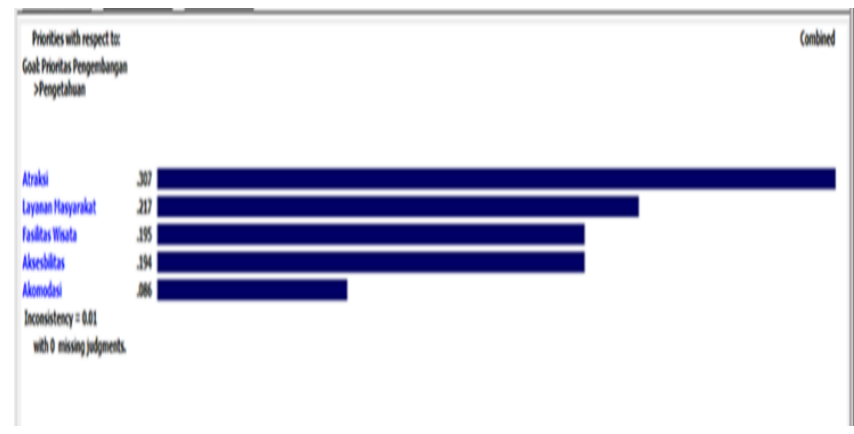

Sumber: Hasil analisis. 2021

Gambar 8. Output AHP Variabel Pengetahuan Pada Kebutuhan Kepariwisataan

\section{b. Variabel Sikap}

Berdasarkan Gambar 9 hasil analisis AHP pada kritera sikap atraksi mendapat prioritas utama untuk dikembangkan dengan nilai bobot 0,270 atau $27 \%$, kemudian prioritas kedua aksesbilitas dengan bobot 0,261 atau $26,1 \%$, kemudian fasilitas wisata dengan bobot 0,218 atau $21,8 \%$, akomodasi dengan bobot 0,167 atau $16,7 \%$ dan layanan masyarakat dengan bobot 0,084 atau $8,4 \%$

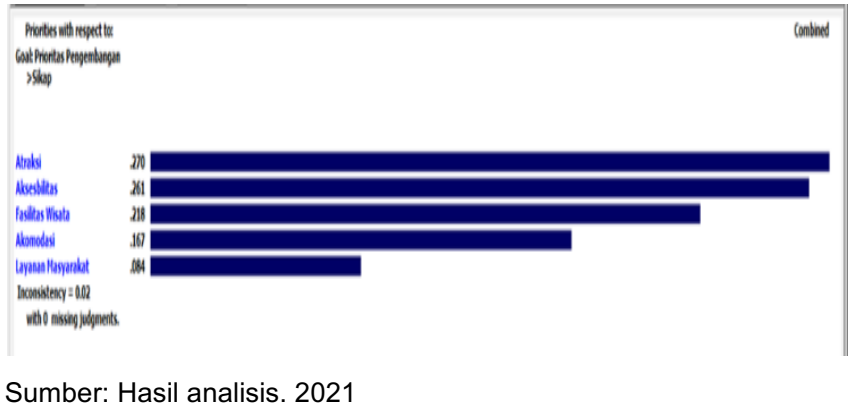

Sumber: Hasil analisis. 2021

Gambar 9. Output AHP Variabel Sikap Pada Kebutuhan Kepariwisataan

\section{c. Variabel Respon}

Berdasarkan gambar 10 hasil analisis AHP pada kritera respon aksesbilitas mendapat prioritas utama dengan nilai bobot 0,266 atau $26,6 \%$, kemudian prioritas kedua fasilitas wisata dengan bobot 0,261 atau $26,1 \%$, kemudian akomodasi dengan bobot 0,224 atau $22,4 \%$ atraksi dengan bobot 0,177 atau $17,7 \%$ dan akomodasi dengan bobot 0,072 atau $7,2 \%$.

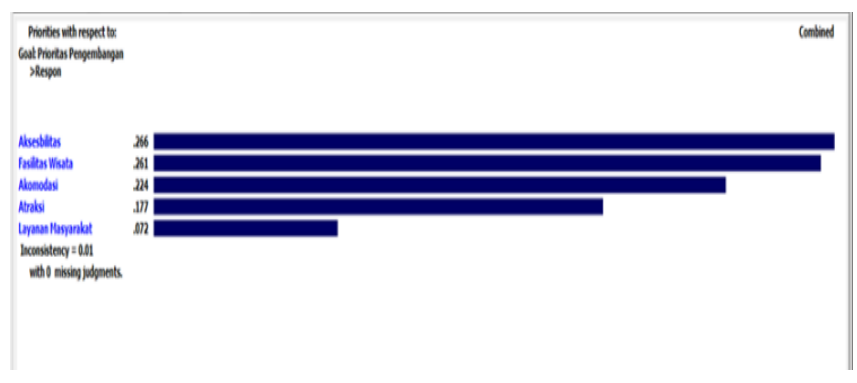

Sumber: Hasil analisis. 2021

Gambar 10. Output AHP Variabel Respon Pada Kebutuhan Kepariwisataan

Berdasarkan hasil perhitungan analisis prioritas pengembangn kesiapan masyarakat Kampung Jawi terkait pemenuhan kebutuhan kepariwisataan yang telah diolah menggunakan aplikasi expert choiche kriteria yang paling diprioritaskan dalam pengembangan Kampung Jawi adalah atraksi dan aksesbilitas dimana pada kriteria pengetahuan aspek atraksi mendapat nilai prioritas tertinggi yaitu sebesar $30,7 \%$. Dan pada kriteria sikap atraksi juga mendapat nilai prioritas tertinggi yaitu $27 \%$ sedangkan pada kriteria respon aksesbilitas menjadi prioritas utama yaitu sebesar $26,6 \%$, aspek atraksi pada kriteria pengetahuan dianggap penting karena atraksi dalam sebuah wisata dianggap icon utama yang dituju oleh wisatawan oleh karena itu pengetahuan dari 
segi atraksi harus terus dikembangkan. Atraksi wisata juga mendapat prioritas utama dari kriteria sikap dimana dalam pengadaan atraksi perlu adanya sikap positif yang harus diberikan masyarakat tujuannya adalah agar dalam pengadaan atraksi wisata muncul ide-ide kreatif dan inovatif dalam penyajiannya dan masyarakat juga dapat ikut serta didalamnya. Kemudahan aksesbilitas juga dianggap penting karena dengan kemudahan akses wisatawan dapat dengan mudah untuk menuju ke Kampung Jawi oleh karena itu perlu adanya tindakan untuk mewujudkan kemudahan akses baik dari segi transportasi maupun media informasi.

\section{5) Uji Konsistensi}

\section{a. Variabel Pengetahuan}

Untuk uji konsistensi dilakukan dengan pengukuran konsistensi dari pertimbangan (judgments) dalam pembandingan berpasangan yang disebut "rasio konsistensi" (consistency ratio) yang bermanfaat untuk mengetahui apakah perlu dilakukan revisi pada matriks pembandingan berpasangan atau tidak. Berikut perhitungan consistency ratio (CR) sebagai berikut:

$$
C R=C I R I
$$

Dimana ketentuan nilai Random Index (RI) yaitu $n(2)=0 ; n(3)=0,58 ; n(4)=0,90 ; n(5)=$ 1,$12 ; \mathrm{n}(6)=1,24 ; \mathrm{n}(7)=1,32 ; \mathrm{n}(8)=1,41 ; \mathrm{n}(9)$ $=1,45$; dan $\mathrm{n}(10)=1,49$.

Dalam menentukan $\mathrm{Cl}$ perlu diketahui terlebih dahulu Jumlah nilai dan Eigenvektor Utama $(\lambda)$

Tabel 7. Eigenvektor Pengetahuan

\begin{tabular}{|l|c|c|c|}
\hline Kriteria & $\begin{array}{c}\text { Jumlah } \\
\text { Nilai }\end{array}$ & $\begin{array}{c}\text { Nilai } \\
\text { Prioritas }\end{array}$ & $\begin{array}{c}\text { Eigenvektor } \\
\text { Utama }(\lambda) \text { (Jumlah } \\
\text { nilai } x \text { Nilai } \\
\text { prioritas) }\end{array}$ \\
\hline Atraksi & 9,127 & 0,307 & 2,801 \\
\hline Aksesbilitas & 5,774 & 0,217 & 1,252 \\
\hline Akomodasi & 6,742 & 0,195 & 1,314 \\
\hline Amenities & 4,749 & 0,194 & 0,921 \\
\hline Awarness & 9,073 & 0,086 & 0,780 \\
\hline \multicolumn{2}{|c|}{ Jumlah } & 1 & 7,068 \\
\hline \multicolumn{2}{|r}{} & & $\begin{array}{l}\lambda \max =7,068 / 5= \\
1,413\end{array}$ \\
\hline
\end{tabular}

Sumber: Hasil analisis. 2021

$$
\begin{aligned}
C & =\frac{\lambda \max -n}{n-1} \\
& =\frac{1,413-5}{5-1} \\
& =-0,896
\end{aligned}
$$

Sehingga didapatkan CR sebagai berikut:

$$
\begin{aligned}
\mathrm{CR} & =\frac{\mathrm{Cl}}{\mathrm{RI}} \\
& =\frac{-0,896}{1,12} \\
& =-0,8 \leq 0,10
\end{aligned}
$$

Menurut hasil perhitungan uji konsistensi oleh peneliti diketahui nilai $\mathrm{CR}$ untuk sub variabel pengetahuan adalah $-0,8$ dimana nilai CR lebih kecil dari $10 \%$ atau 0,10. Maka judgments dari penilai dalam melakukan pembandingan berpasangan antar kriteria dianggap konsisten dan dapat diterima.

b. Variabel Sikap

Tabel 8. Eigenvektor Sikap

\begin{tabular}{|l|c|c|c|}
\hline \multicolumn{1}{|c|}{ Kriteria } & $\begin{array}{c}\text { Jumlah } \\
\text { Nilai }\end{array}$ & $\begin{array}{c}\text { Nilai } \\
\text { Prioritas }\end{array}$ & $\begin{array}{c}\text { Eigenvektor } \\
\text { Utama }(\boldsymbol{\Lambda}) \\
\text { (Jumlah nilai x } \\
\text { Nilai prioritas) }\end{array}$ \\
\hline Atraksi & 8,075 & 0,270 & 2,180 \\
\hline Aksesbilitas & 7,938 & 0,261 & 2,071 \\
\hline Akomodasi & 6,066 & 0,218 & 1,322 \\
\hline Amenities & 7,565 & 0,167 & 1,263 \\
\hline Awarness & 3,024 & 0,084 & 0,254 \\
\hline \multicolumn{2}{|c|}{ Jumlah } & 1 & 7,09 \\
\hline \multicolumn{2}{|r|}{} & & $\begin{array}{c}1,418 \\
\text { max }=7,09 / 5=\end{array}$ \\
\hline
\end{tabular}

Sumber: Hasil analisis. 2021

$$
\begin{aligned}
C & =\frac{\lambda \max -n}{n-1} \\
& =\frac{1,418-5}{5-1} \\
& =-0,895
\end{aligned}
$$

Sehingga didapatkan CR sebagai berikut:

$$
\begin{aligned}
\mathrm{CR} & =\frac{\mathrm{Cl}}{\mathrm{RI}} \\
& =\frac{-0,895}{1,12} \\
& =-0,79 \leq 0,10
\end{aligned}
$$


Menurut hasil perhitungan uji konsistensi oleh peneliti diketahui nilai $\mathrm{CR}$ untuk sub variabel sikap adalah $-0,79$ dimana nilai CR lebih kecil dari $10 \%$ atau 0,10 . Maka judgments dari penilai dalam melakukan pembandingan berpasangan antar kriteria dianggap konsisten dan dapat diterima.

\section{c. Variabel Respon}

Tabel 9. Eigenvektor Sikap

\begin{tabular}{|l|c|c|c|}
\hline Kriteria & $\begin{array}{c}\text { Jumlah } \\
\text { Nilai }\end{array}$ & $\begin{array}{c}\text { Nilai } \\
\text { Prioritas }\end{array}$ & $\begin{array}{c}\text { Eigenvektor } \\
\text { Utama }(\boldsymbol{\lambda}) \\
\text { (Jumlah nilai x } \\
\text { Nilai prioritas) }\end{array}$ \\
\hline Atraksi & 8,79 & 0,266 & 2,338 \\
\hline Aksesbilitas & 7,766 & 0,261 & 2,026 \\
\hline Akomodasi & 6,91 & 0,224 & 1,547 \\
\hline Amenities & 5,692 & 0,177 & 1,007 \\
\hline Awarness & 2,865 & 0,072 & 0,206 \\
\hline \multicolumn{2}{|c|}{ Jumlah } & 1 & 7,124 \\
\hline \multicolumn{2}{|r|}{} & & $\begin{array}{c}1,424 \\
\text { max }=7,124 / 5=\end{array}$ \\
\hline
\end{tabular}

Sumber: Hasil analisis. 2021

$$
\begin{aligned}
C & =\frac{\lambda \max -n}{n-1} \\
& =\frac{1,424-5}{5-1} \\
& =-0,894
\end{aligned}
$$

Sehingga didapatkan CR sebagai berikut:

$$
\begin{aligned}
\mathrm{CR} & =\frac{\mathrm{Cl}}{\mathrm{RI}} \\
& =\frac{-0,894}{1,12} \\
& =-0,79 \leq 0,10
\end{aligned}
$$

Menurut hasil perhitungan uji konsistensi oleh peneliti diketahui nilai CR untuk sub variabel respon adalah $-0,79$ dimana nilai CR lebih kecil dari $10 \%$ atau 0,10 . Maka judgments dari penilai dalam melakukan pembandingan berpasangan antar kriteria dianggap konsisten dan dapat diterima.

\section{SIMPULAN}

Dari hasil analisis yang telah dilakukan dapat ditarik kesimpulan sebagai berikut:

1. Berdasarkan hasil analisis tingkat dan posisi kesiapan masyarakat diperoleh informasi sebagai berikut:
a. Untuk tingkat pengetahuan
kesiapan dari segi rata-rata masyarakat

Kampung Jawi sudah mengetahui terkait lima komponen dalam pemenuhan kebutuhan wisata yaitu atraksi, akomodasi, aksesbilitas, fasilitas wisata dan layanan masyarakat. Adapun nilai tertinggi dari kesiapan terkait pengetahuan adalah pengetahuan terkait layanan masyarakat yaitu $22 \%$ dimana masyarakat sudah mengetahui bagaimana memberikan pelayanan yang baik yaitu dengan memberikan pelayanan jasa yang dapat dinikmati oleh wisatawan serta bersikap ramah dalam berinteraksi terhadap wisatawan. dan nilai pengetahuan terendah yaitu aksesbilitas dengan niali $18 \%$, dimana masyarakat belum mengetahui hal apa yang harus dilakukan untuk menciptakan kemudahan akses baik transportasi maupun media informasi.

b. Nilai tertinggi kesiapan untuk sub variabel sikap yaitu atraksi wisata dan fasilitas wisata dengan nilai $21 \%$ dimana dalam pengadaan atraksi wisata dan fasilitas wisata masyarakat sudah memberikan sikap positif yaitu dengan membuat ide-ide kreatif dan inovatif seperti pengadaan spot foto, pembuatan lampion tepi sungai, pengadaan kesenian, pembuatan konsep yang unik pada setiap bangunan yang ada di angkringan Kampung Jawi dan masyarakat juga sudah ikut serta dalam pengadaannya. Sedangkan untuk nilai terendah yaitu sikap terhadap aksesbilitas dan akomodasi sebesar $19 \%$ hal ini dikarenakan didalam pengadaan kemudahan transportasi dan media informasi belum optimal. Pengadaan tempat penginapan juga belum terkelola dengan baik.

c. Untuk respon yang diberikan masyarakat sudah cukup baik karena masyarakat sudah mengimplementasikan wujud dukungan dari sikap yang diberikan seperti sudah adanya dukungan masyarakat baik dalam program maupun dukungan lainnya seperti strategi pengembngan dan pembentukan pengelola disana juga tidak ada persaingan antar warga dalam hal pemenuhan kebutuhan pariwisata untuk wisatawan. namun dalam pengimplementasiannya masih perlu 
pengoptimalan pengembangan untuk kedepannya. Untuk nilai kesiapan dari segi respon niali tertinggi yaitu fasilitas wisata dan aksesbilitas sebesar $21 \%$ dimana dalam pengadaan fasilitas wisata masyarakat ikut memberi dukungan tenaga dalam pembangunanya secara gotong-royong dan untuk dukungan kemudahan aksesbilitas masyarakat sudah mulai melakukan perbaikan jalan dan pengelolaan strategi media informasi agar wisatawan dapat mengakses dengan mudah. untuk nilai terendah ada pada akomodasi yaitu sebesar $18 \%$ dikarenakan masih belum banyak minat wisatawan untuk bermalam di Kampung Jawi oleh karena itu dukungan masyarakat dalam hal akomodasi masih rendah.

d. Berdasarkan hasil perhitungan analisis point kesiapan Masyarakat Kampung jawi yaitu sebesar 18,3 dimana menurut tabel posisi kesiapan masyarakat berada pada posisi preparation yaitu posisi dimana masyarakat sudah mulai mengorganisir diri. adapun bentuk organisir diri di Kampung Jawi meliputi adanya keterlibatan masyarakat dalam pengembangan dan pembangunan fasilitas-fasilitas yang ada di Kampung Jawi seperti pengadaan bangunan gedung serba guna untuk pementasan kesenian, pembuatan sanggar seni, pembuatan angkringan dengan konsep kebudayaan dan kuliner-kuliner khas Jawa, dimana yang menjadi pelaku penyedia jasa yaitu masyarakat lokal di Kampung Jawi serta sudah mulai melakukan pengembangan fasilitas-fasilitas lainnya. Selain itu sudah mulai membentuk atraksi yang dapat ditawarkan kepada wisatawan seperti paket edukasi kebudayaan dimana wisatawan dapat belajar keseniankesenian jawa, bahasa dan dolanandolanan jawa. Masyarakat juga mulai mengadakan pelatihan-pelatihan kesenian dan mulai membentuk lembaga pengelola untuk membuat strategi perencanaan untuk kedepannya, selain lembaga pengelola juga dibentuk kelompok seni untuk mengelola keseniankesenian yang ada. Untuk kemudahan informasi masyarakat mulai menyusun strategi promosi melalui media sosial dan mulai melakukan perbaikan-perbaikan akses jalan meskipun belum optimal. Masyarakat juga sudah mengupayakan penyediaan tempat penginapan untuk wisatawan yang ingin bermalam namun masih terbatas dan belum terkelola dengan baik

2. Berdasarkan hasil analisis prioritas pengembangn kesiapan masyarakat Kampung Jawi terkait pemenuhan kebutuhan kepariwisataan kriteria yang paling diprioritaskan dalam pengembangan Kampung Jawi adalah atraksi dan aksesbilitas dimana pada kriteria pengetahuan aspek atraksi mendapat nilai prioritas tertinggi yaitu sebesar $30,7 \%$. Pada kriteria sikap atraksi juga mendapat nilai prioritas tertinggi yaitu $27 \%$ sedangkan pada kriteria respon aksesbilitas menjadi prioritas utama yaitu sebesar $26,6 \%$, aspek atraksi pada kriteria pengetahuan dianggap penting karena atraksi dalam sebuah wisata dianggap icon utama yang dituju oleh wisatawan oleh karena itu pengetahuan dari segi atraksi harus terus dikembangkan. Atraksi wisata juga mendapat prioritas utama dari kriteria sikap dimana dalam pengadaan atraksi perlu adanya sikap positif yang harus diberikan masyarakat tujuannya adalah agar dalam pengadaan atraksi wisata muncul ideide kreatif dan inovatif dalam penyajiannya dan masyarakat juga dapat ikut serta didalamnya. Kemudahan aksesbilitas juga dianggap penting karena dengan kemudahan akses wisatawan dapat dengan mudah untuk menuju ke Kampung Jawi oleh karena itu perlu adanya tindakan untuk mewujudkan kemudahan akses baik dari segi transportasi maupun media informasi.

\section{REFERENSI}

Adriansyyah, Vedyana.2020. Keunikan Kampung Jawi. Diakses pada tanggal 28 Maret 2021. Ayosemarang.com

Azwar.2007. Kapita Selekta Kuesioner Pengetahuan dan Sikap dalam Penelitian Kesehatan.Jakarta Salemba Medika.

Handayani, Tati. Mira Rahmi.2018.Analisis Kesiapan Desa Mekar Agung 
Kecamatan Cibadak Kabupaten Lebak Banten Sebagai Desa Wisata Syariah. Garuda.ristekbrin.ac.id

Husein Umar. 2013. Metode Penelitian untuk Skripsi dan Tesis Bisnis Edisi Kedua. Jakarta: Rajawali Pers. (ID): Kementerian Pariwisata.

Lazuardi, Fahmi Ramadhan.2015.Arahan Peningkatan Kesiapan Masyarakat Terhadap Rencana Pembangunan Kawasan Industri Di Kecamatan Wongsorejo Kabupaten Banyuwangi. Tugas akhir institut teknologi sepuluh november

Muh Nurtanzis. Metode Analytic Hierarhy Proses (AHP).mr.iyes@yahoo.co.id

Nyoman, Ni. I Nyoman Sukamara.2020. Kajian Kesiapan Desa Bukit Sebagai Desa Wisata Nawa Satya di Kabupaten Karangasem, Bali.core.ac.uk

Porwanti Apri N.2002. Kajian Kesiapan

Masyarakat Terhadap Kebutuhan Wisatawan di Kawasan Wisata

Agro Bangunkerto Sleman, Yogyakarta. eprints.undip.ac.id

Ruth W. Edwards, Pamela Jumper-Thurman, et.al. 2000. Community readiness. Journal of community psychology

Saaty, Thomas L, dan Vargas, Luis G., 2001. Models Methods, Concepts \& applications of the Analytic Hierarchy Process, Springer Science.

Sugiyono. 2016. Metode Penelitian Kuantitatif Kualitatif R\&D. Bandung: CV. Alfabet 